\title{
A study of spectrum and outcome of liver diseases in pregnant women at BRD medical college
}

\author{
Amrita Tiwari*, Vani Aditya, Reena Srivastava, Geeta Gupta
}

Department of Obstetrics and Gynecology, BRD Medical College, Gorakhpur, Uttar Pradesh, India

Received: 15 June 2017

Accepted: 08 July 2017

\section{*Correspondence:}

Dr. Amrita Tiwari,

E-mail: dramritatiwari.kgmc@gmail.com

Copyright: (C) the author(s), publisher and licensee Medip Academy. This is an open-access article distributed under the terms of the Creative Commons Attribution Non-Commercial License, which permits unrestricted non-commercial use, distribution, and reproduction in any medium, provided the original work is properly cited.

\begin{abstract}
Background: Different spectrum of liver disease can affect outcome of pregnancy. The incidence of liver disorders in pregnancy varies in different parts of the world. The present study was designed to see the incidence, spectrum, and outcome of liver disease in pregnancy.

Methods: All pregnant women with deranged liver profile, attending antenatal clinic and labour room in the department of Obstetrics and Gynecology of BRD Medical College over the period of one year (August 2015 to July 2016) were included in the study. Enrolled cases were followed up till discharge in respect to maternal and fetal outcome.

Results: Liver disease was found in 214 (2.37\%) cases out of 9011 pregnancies. Pregnancy specific liver disease was the most common type (85.98\%). Among pregnancy specific liver disease Hypertensive disorders of pregnancy was the commonest abnormality (66.35\%). Rest were Cholestasis, Acute viral hepatitis, Chronic liver disease, Hyperemesis gravidarum, Acute fatty liver of pregnancy. Out of 214, 22 patients dropped out. Overall maternal and perinatal mortality were $13.02 \%$ and $29.17 \%$ respectively.

Conclusions: Liver disease in pregnancy is not uncommon and it can seriously affect pregnancy outcome if not treated properly on time. Early diagnosis (by clinical suspicion and blood investigation) and timely intervention can improve maternal and fetal outcome in pregnancy with liver disease.
\end{abstract}

Keywords: Liver disease, Maternal, Outcome, Pregnancy, Spectrum

\section{INTRODUCTION}

Liver as a vital organ plays important role for various metabolic changes during pregnancy. Pregnancy causes very few alterations in the results of standard liver tests. Findings such as elevated serum alkaline phosphatase levels, palmar erythema, and spider angiomas, which might suggest liver disease, are commonly found during normal pregnancy.

Liver disorders comprise up to $3 \%$ of all pregnancy complications. ${ }^{1}$
It is customary to divide liver diseases complicating pregnancy into three broad categories. ${ }^{2}$

- Diseases specifically related to pregnancy (resolve spontaneously or following delivery) are hepatic dysfunction from hyperemesis gravidarum, intrahepatic cholestasis, acute fatty liver, and hepatocellular damage with preeclampsia.

- Acute hepatic disorders that is coincidental to pregnancy, such as acute viral hepatitis.

- Chronic liver diseases that predate pregnancy, such as chronic hepatitis, cirrhosis, or esophageal varices. 
The key to maternal and fetal wellbeing is an early diagnosis and appropriate management. ${ }^{3}$ Therefore, the present study was designed to see the incidence, spectrum, and outcome of liver disease in pregnancy.

\section{METHODS}

After obtaining permission from ethical committee, the present study was conducted in all pregnant women with previously diagnosed or suspected liver disease, attending antenatal clinic and labour room in the department of Obstetrics and gynaecology of BRD Medical College over the period of one year (August 2015 to July 2016). Diagnosed cases were followed up till discharge. In suspected cases liver function tests were done and if liver disease was found they were followed up till discharge. Spectrum of different liver diseases and maternal and foetal outcome observed.

\section{RESULTS}

Liver disease was found in $214(2.37 \%)$ pregnant women out of 9011 pregnancies at BRDMC Gorakhpur. Most of the patients belong to younger age group (20-29 years) with low socioeconomic status $(84.56 \%)$ living in rural areas $(66.82 \%)$ and educated upto primary and secondary standard $(69.15 \%)$. Majority of patients were Hindu $(63.38 \%)$. Major proportion was unbooked $(81.3 \%)$, primigravida $(53.73 \%)$ who came in third trimester $(85.04 \%)$ at term $(71.02 \%)$ (Table 1$)$.

Table 1: Socio-demographic distribution.

\begin{tabular}{|c|c|c|c|}
\hline Characteristics & & Cases of liver disease $(n=214)$ & $\%$ \\
\hline \multirow{4}{*}{ Age Group } & $<20$ & 8 & 3.73 \\
\hline & $20-29$ & 147 & 68.69 \\
\hline & $30-40$ & 53 & 24.77 \\
\hline & $>40$ & 6 & 2.8 \\
\hline \multirow{2}{*}{ Religion } & Hindu & 135 & 63.38 \\
\hline & Muslim & 78 & 36.62 \\
\hline \multirow{4}{*}{ Educational status } & illiterate & 49 & 22.9 \\
\hline & Primary & 91 & 42.52 \\
\hline & Secondary & 57 & 26.63 \\
\hline & Higher & 17 & 7.94 \\
\hline \multirow{2}{*}{ Residence } & Rural & 143 & 66.82 \\
\hline & Urban & 71 & 33.18 \\
\hline \multirow{3}{*}{ Socioeconomic status } & Upper & 4 & 1.87 \\
\hline & Middle & 97 & 45.12 \\
\hline & Lower & 113 & 52.79 \\
\hline \multirow{2}{*}{ Antenatal care status } & Booked & 40 & 18.7 \\
\hline & Unbooked & 174 & 81.3 \\
\hline \multirow{2}{*}{ Parity } & Primigravida & 115 & 53.73 \\
\hline & Multigravida & 99 & 46.26 \\
\hline \multirow{2}{*}{ Gestational age at presentation } & Term & 152 & 71.02 \\
\hline & Preterm & 62 & 28.97 \\
\hline \multirow{3}{*}{ Trimester of presentation } & $1^{\text {st }}$ & 4 & 1.87 \\
\hline & $2^{\text {nd }}$ & 28 & 13.08 \\
\hline & $3^{\text {rd }}$ & 182 & 85.04 \\
\hline
\end{tabular}

Table 2: Spectrum of liver disease based on aetiology.

\begin{tabular}{|lll|}
\hline Etiology of liver disease & Cases of liver disease $(\mathbf{n = 2 1 4})$ & $\%$ \\
\hline Hypertensive disorders of pregnancy & 142 & 66.35 \\
\hline cholestasis & 36 & 16.82 \\
\hline Hyperemesis gravidarum & 4 & 1.86 \\
\hline Acute fatty liver of pregnancy & 2 & 0.93 \\
\hline acute viral hepatitis & 12 & 5.6 \\
\hline chronic liver disease & 11 & 5.14 \\
\hline Others* & 7 & 3.27 \\
\hline
\end{tabular}


Hypertensive disorders of pregnancy were the most common liver disease $142(66.35 \%)$, followed by cholestasis $36(16.82 \%)$ and viral hepatitis $23(10.74 \%)$. Majority $184(85.98 \%)$ patients had pregnancy specific liver disease (Table 2 and Table 3 ).

Table 3: Spectrum of liver disease.

\begin{tabular}{|lll|}
\hline Nature of liver disease & $\begin{array}{l}\text { Cases of liver } \\
\text { disease }(\mathrm{n}=214)\end{array}$ & $\%$ \\
\hline Pregnancy specific & 184 & 85.98 \\
\hline Pregnancy nonspecific & 30 & 14.02 \\
\hline
\end{tabular}

HELLP syndrome developed in $15.62 \%$ of patients with liver disease.

Twenty eight out of thirty patients developed HELLP due to Hypertensive disorders of pregnancy and in 2 patients the cause was AFLP. DIC developed in $24.48 \%$ patients, $14.58 \%$ had ARF, $3.64 \%$ had hepatic encephalopathy (HE).

$30.72 \%$ patients developed $\mathrm{PPH}, 43.75 \%$ patients required blood transfusion and $26.56 \%$ patients required ICU admission. Over all maternal mortality was $13.02 \%$. (Table 4).

Table 4: Maternal outcome in liver disease.

\begin{tabular}{|lll|}
\hline $\begin{array}{l}\text { Maternal } \\
\text { Complications }\end{array}$ & No of cases $(\mathbf{n = 1 9 2})$ & $\%$ \\
\hline HELLP & 30 & 15.62 \\
\hline DIC & 47 & 24.48 \\
\hline ARF & 28 & 15.58 \\
\hline HE & 7 & 3.64 \\
\hline PPH & 59 & 30.72 \\
\hline BT & 84 & 43.75 \\
\hline ICU admission & 51 & 26.56 \\
\hline Mortality & 25 & 13.02 \\
\hline
\end{tabular}

HELLP: Hemolysis, Elevated Liver enzymes, Low Platelet count; DIC: Disseminated Intravascular Coagulopathy; ARF: Acute Renal Failure; HE: Hepatic Encephalopathy; PPH: PostPartum Haemorrhage; BT: Blood Transfusion

Prematurity was found in $32.29 \%$ newborn. Over all perinatal death was $29.17 \%$, out of which $16.14 \%$ babies were still born, $13.54 \%$ died in utero and early neonatal death (within 7 days) occurred in $13.02 \%$ of newborn. Requirement of NICU admission was $24.47 \%$ (Table 5).

Table 5: Fetal outcome in liver disease.

\begin{tabular}{|lll|}
\hline Fetal complications & Number $(\mathbf{n}=192)$ & $\%$ \\
\hline Prematurity & 62 & 32.29 \\
\hline Still birth & 31 & 16.14 \\
\hline Early neonatal death & 25 & 13.02 \\
\hline Requirement of & 47 & 24.47 \\
NICU admission & 56 & 29.17 \\
\hline Mortality & & \\
\hline
\end{tabular}

\section{DISCUSSION}

The overall mortality attributed to liver disorders in pregnancy has dramatically decreased in the past few years because of better understanding of the physiologic changes that occur during pregnancy, early recognition of clinical and laboratory abnormalities that help in identifying the aetiology and its effective management in a timely manner. The overall incidence of liver disorder in pregnancy in our institution was $2.37 \%$. Similar incidence was reported in other prospective studies. ${ }^{1,3-5}$ Three other studies revealed lesser percentage of pregnant women with liver dysfunction. ${ }^{6-8}$

In present study, most of the women $(68.69 \%)$ belonged to age group 20-29years. Majority $(63.38 \%)$ of the patients were Hindu. $69.15 \%$ patients were educated upto primary and secondary standard, $84.56 \%$ patients were from lower socioeconomic status, $66.82 \%$ patients were from rural area, $81.3 \%$ patients were unbooked. Majority $(53.73 \%)$ of affection was found in primigravida in third trimester of pregnancy $(76.63 \%)$ and $71.02 \%$ patients came at term. The demographic profile of present study was comparable with other studies. ${ }^{3,5,6,9}$ In two prospective studies by Swati $\mathrm{S}$ et al and Aparajita $\mathrm{S}$ et al, majority of the patients were from urban area who had better awareness of the possible complications during pregnancy, thereby leading to less maternal mortality.

The reported proportion of pregnancy-specific liver diseases among affected patients varied from $67 \%$ to $89 \%$ in previous studies. ${ }^{10-12}$ In present study, $86 \%$ of affected patients had pregnancy-specific liver disease. This is similar to finding of $83.25 \%$ in study by Nalini et al and $76 \%$ in study by CL Ch'ng et al. ${ }^{13,1}$

In our study, $14.02 \%$ women had liver disorders which were not specific to pregnancy and consisted of infective hepatitis and others (cause could not be found). In present study Hepatitis-B was the cause in all cases of chronic liver disease. ${ }^{11}$

Among pregnancy specific liver disease Hypertensive disorders of pregnancy was the commonest abnormality $(66.35 \%)$. Two other studies also showed similar result. ${ }^{1,4}$ Where as in prospective study done by Swati et al and Jayanthi et al, viral hepatitis was the most common cause of liver disease. ${ }^{3,9}$

Total 214 patients with derranged LFT were included in study. Twenty-two patients dropped out. Maternal and fetal outcome was studied in 192 patients. Out of 192 patients 25 patients died and 167 patients discharged.

Maternal mortality was $13.02 \%$ (25 out of 192patients) due to liver disease. Most women died because of Hypertensive disorders of pregnancy (21 out of 25). This is comparable with $19 \%$ overall maternal mortality in prospective study by Umang $\mathrm{R}$ et al. ${ }^{4}$ Divyakala et al in their prospective study reported $75.68 \%$ maternal 
mortality. ${ }^{6}$ Many studies are with lower maternal mortality in comparision to our study. $3,6,9,13$

In the present study, HELLP syndrome developed in $15.62 \%$ of patients. In which 28 out of 30 were in women with Hypertensive disorders of pregnancy and 2 in women with AFLP. This is in accordance with result of various prospective studies in India. ${ }^{3,5,13}$ Few other Indian studies, one by Umang $\mathrm{R}$ et al in Mumbai and other prospective study by Divyakala et al in Karnataka showed much higher incidence of HELLP Syndrome (61.11\% and $75.68 \%$ respectively). In our setting DIC developed in $47(24.48 \%)$ patients, while Acute renal failure and Hepatic Encephalopathy developed in 28 $(15.58 \%)$ and $7(3.64 \%)$ of Patients with liver disease respectively. These findings are similar to various prospective studies. ${ }^{3,4}$

PPH was seen in $30.72 \%$ of patients, all required blood transfusion. Requirement of blood transfusion was found in $43.75 \%$ of patients with liver disease. Most of the transfusion requirements were because of development of $\mathrm{PPH}$ and rest for coexisting anaemia.

Nearly $27 \%$ of the patients required ICU admission. Intensive care monitoring was mainly needed in patients with AFLP, Hepatitis-E, Eclampsia and preeclampsia patients who ultimately developed pulmonary oedema. One prospective study done in Bhopal, reported development of PPH in $60 \%$ of patients and all managed by blood transfusion.

This study reported $100 \%$ ICU admission. ${ }^{3}$ In contrast to this another prospective study done in Ludhiana showed that PPH developed in only $2 \%$ of patients, requirement of blood transfusion in $12 \%$ of patients and ICU admission in nearly $4 \%$ of patients. ${ }^{5}$

In present study, perinatal mortality was $29.17 \%$ (56 out of 192 patients) due to liver disease. Among 56 perinatal deaths 43 were in patients with Hypertensive disorders of pregnancy. This is comparable with $35.4 \%$ overall perinatal mortality in prospective study by Umang $\mathrm{R}$ et al, with highest mortality was in patients with AFLP $(66.66 \%)$. These finding are also comparable with other two studies. ${ }^{9,13}$

In the present study $32.29 \%$ babies were premature, still birth was $16.14 \%$, IUD were $13.54 \%$, Early neonatal death was in $13.02 \%$. NICU admission was required in $24.47 \%$ newborns. This is comparable with report of other studies. ${ }^{3,5,6,13}$

The higher maternal and foetal morbidity and mortality appear to be due to lower socioeconomic condition and illiteracy, leading to unawareness regarding pregnancy specific conditions and their outcome. Other factors include poor nutrition, prevalence of anaemia, lack of antenatal check-up, delay in seeking medical advice and delay in referral to the tertiary care hospital.

\section{CONCLUSION}

Pregnancy-specific disorders especially hypertensive disorder of pregnancy came out to be the leading cause of liver dysfunction during pregnancy. Liver disease has deleterious effect on pregnancy outcome with increased maternal and foetal morbidity and mortality. To conclude timely diagnosis by proper antenatal check-up, early interventions and intensive monitoring of both mother and foetus with the team work of obstetrician, physician, gastroenterologist, and anaesthetist can prevent and reduce feto-maternal morbidity and mortality.

Funding: No funding sources

Conflict of interest: None declared

Ethical approval: The study was approved by the Institutional Ethics Committee

\section{REFERENCES}

1. Ch'ng CL, Morgan M, Hainsworth I, Kingham JG. Prospective study of liver dysfunction in pregnancy in Southwest Wales. Gut. 2002;51:876-80.

2. Cunningham FG, Leveno KJ, Bloom SL, Spong CY, Dashe JS, Hoffman BL et al. Williams Obstetrics $24^{\text {th }}$ edition, Mcgraw Hills; 2014.

3. Sharma S, Aherwar R, Jawade S. Maternal and fetal outcome in jaundice complicating pregnancy: a prospective study. Internat $\mathbf{J}$ Reproduct Contracept Obstetr Gynecol. 2016;5(4):1084-7.

4. Rathi M, Bapat P, Rathi P. Abraham, Effect of liver disease in maternal and foetal outcome-A prospective study. Indian J Gastroenterol. 2007;26;61.

5. Dsouza AS, Gupta G, Sandeep SG, Katumalla FS, Goyal S. Maternal and fetal outcome in liver diseases of pregnancy-A tertiary hospital experience. Internat J Scient Res Publicat. 2015;21(25):27.

6. Karegoudar D, Dhirubhai PR, Dhital M, Amgain K. A study of liver disorder and its consequences in pregnant women with jaundice in tertiary care centre in Belgaum, Karnataka, India. Mortality. 2014;28:75-68.

7. Acharya N, Acharya S, Shukla S, Athvale R, Shaveta. Study of Jaundice in Pregnancy. Glb J of Med research. 2013;13:25-9.

8. Oladokun A, Otegbayo JA, Adeniyi AA. Maternal and fetal outcomes of jaundice in regnancy at the University College Hospital, Ibadan. Niger J Clin Pract. 2009;12(3):277-80.

9. Krishnamoorthy J, Murugesan A: Jaundice during pregnancy: maternal and fetal outcome. International Journal of Reproduction, Contraception, Obstetrics and Gynecology Krishnamoorthy J et al. Int J Reprod Contracept Obstet Gynecol. 2016;5(8):2541-5.

10. Wong HY, Tan JYL, Lim CC. Abnormal liver function tests in the symptomatic pregnant patient: the local experience in Singapore. Ann Acad Med Singapore. 2004;33:204-8. 
11. Tank PD, Nandanwar YS, Mayadeo NM. Outcome of pregnancy with severe liver disease. Int J Gynecol Obstet. 2002;76:27-31.

12. Harish K, Nitha R, Harikumar R. Prospective evaluation of abnormal liver function tests in pregnancy. Trop Gastroenterol. 2005;26:188-93.

13. Mishra N, Mishra VN, Thakur P. Study of abnormal liver function test during pregnancy in a tertiary care hospital in Chhattisgarh. J Obstetr Gynecol Ind. 2016 ;66(1):129-35.

Cite this article as: Tiwari A, Aditya V, Srivastava R, Gupta G. A study of spectrum and outcome of liver diseases in pregnant women at BRD medical college. Int J Reprod Contracept Obstet Gynecol 2017;6:3641-5. 